\title{
A Study on the Connotation of the Decoration Colors and Patterns of Yi Architecture
}

\author{
Tianlin Su \\ College of Urban Planning and Architecture, Southwest Minzu University, Chengdu, China \\ Email: 962761697@qq.com
}

How to cite this paper: Su, T.L. (2020) A Study on the Connotation of the Decoration Colors and Patterns of Yi Architecture. Open Access Library Journal, 7: e6686. https://doi.org/10.4236/oalib.1106686

Received: August 3, 2020

Accepted: August 17, 2020

Published: August 20, 2020

Copyright $\odot 2020$ by author(s) and Open Access Library Inc.

This work is licensed under the Creative Commons Attribution International License (CC BY 4.0).

http://creativecommons.org/licenses/by/4.0/

\section{(c) (i) Open Access}

\begin{abstract}
Architecture is the carrier of national culture, and architectural decoration embodies the extension of residential functions from the material realm to the spiritual realm. This article starts from the use and meaning of the architectural decoration colors of the $\mathrm{Yi}$, and the use and meaning of totem decoration patterns. Analyzed the use and symbolic meaning of the decorative colors and patterns in the Yi buildings, so that everyone could better understand the connotation of the decorative colors and patterns in the Yi buildings. What's more, it pointed out that the use of the Yi building decorations has far-reaching significance for the inheritance of the traditional national architectural culture.
\end{abstract}

\section{Subject Areas}

Architecture

\section{Keywords}

Yi Nationality, Architectural Decoration, Colors and Patterns, Connotation

\section{Introduction}

The Yi is mainly distributed in the southwest region. It is one of the seven major minorities in China. Yi has its own mythological origins, ancient Yi characters and mysterious Bimo culture, and has extensive influence on the culture of other ethnic minorities in the southwest. The Yi has a considerable number of oral narrations of epics and myths about the philosophical views of the primitive universe (Wen Quan, 2015) [1]. Yi is a unique and imaginative minority. They also have a rich culture of architectural decoration colors. The unique architectural cultural heritage and ethnic characteristics of the Yi are the decorations of the Yi buildings. Research has laid a solid foundation. In recent years, under the major 
policies of the Party and the state to promote ecological civilization, new countryside and modernization, the traditional settlements of the Yi are also facing a series of practical contradictions such as renewal and reconstruction. Due to inconvenient transportation and poor cultural information, the decline of architectural decoration culture in remote areas is serious. Under this historical background, a deep understanding of the symbolic meaning of Yi architectural decoration and its reasonable use in the construction of new rural areas will do favour in the protection and inheritance of Yi people's traditional architectural decoration. It can not only enable the cultural spirit of ethnic minorities to be fully inherited and carried forward, but also Adapting to the trends and laws of modern human settlements and cultural development in remote areas has important social historical significance and social practical significance. The color decoration of traditional Yi buildings mainly includes the combination of red, yellow and black colors in their decoration and the decoration of detailed totem patterns. The detailed totem decoration mainly includes the patterns of plants, flowers, animals and natural landscapes. The decorative colors and totem patterns of the Yi nationality's traditional buildings reflect the extension of the structure and function of the Yi nationality's architecture from the natural development of the traditional material culture to the spiritual culture(Fan Mi \& Cheng Bin, 2008) [2]. It not only enriches the actual decoration space and its visual effects of traditional Yi buildings, but also fully expresses the characteristics of traditional Yi buildings and its long-standing traditional national culture.

\section{The Use and Connotation of Red, Yellow, and Black in the Decorative Colors of Yi Arctecture}

\subsection{The Use and Connotation of Black in Yi Architectural Decoration}

Architectural color is not only a decorative art (Song Laifu, 2006) [3], but also a choice of aesthetic value for living habits and folklore consciousness, folklore psychology or national culture. Due to the influence and restriction of the natural ecology and geographical environment conditions in minority areas, the color of the building naturally forms an important sign that reflects the traditional cultural characteristics of minorities. The traditional building structure and colors of the Yi are mostly reflected in the uniqueness of building materials (Chen Xiaoqin \& Tang Liying, 2019) [4]. The Yi in Liangshan admire black most, and people there like to use black paint to decorate the exterior walls of their houses (Refer to Figure 1). At first, people thought that cultural customs of admiring for black mainly originated from the Yi people's understanding and response to their life and the natural environment, and gradually transformed them into important traditional culture and religious beliefs in their daily life and work. In addition, The admiration of black is closely related to the geographic location and specific living conditions of the Yi district. For the Yi people who have been hunting for a long time and living in the cold mountainous area, black is 


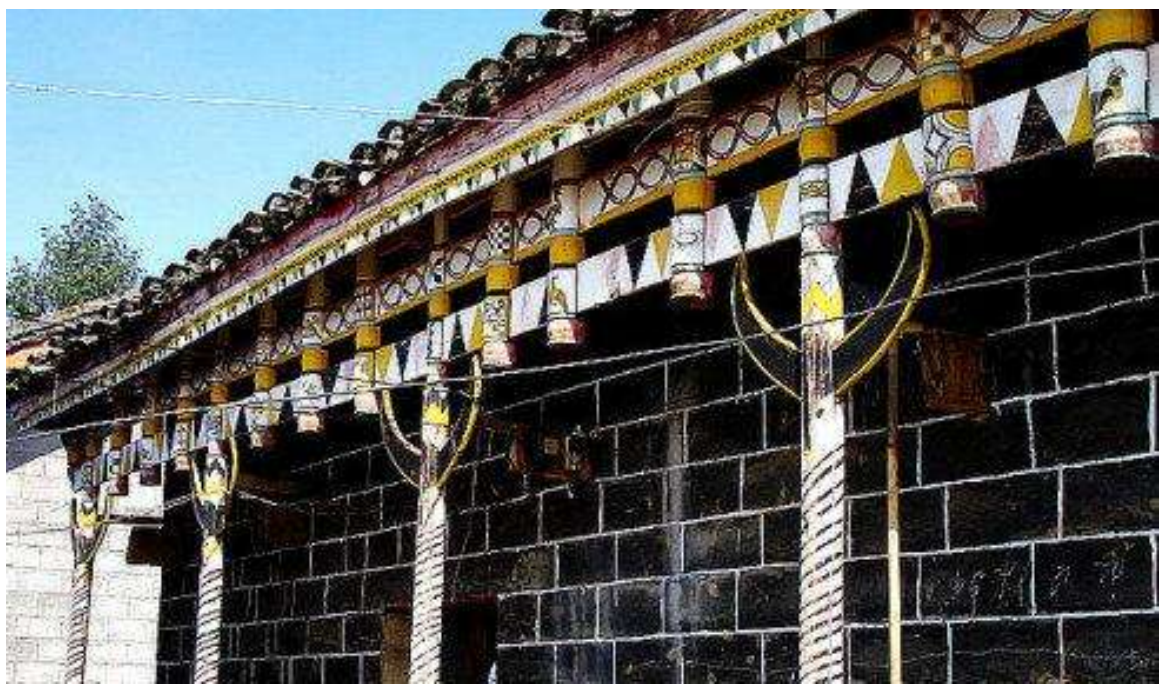

Figure 1. Buildings decorated with black paint on the exterior walls (photo source: Internet).

undoubtedly an important natural protection color. The ethnic culture and traditions have penetrated and used in the interior and exterior design and decoration of many other Yi arctecture. The inner walls of Yi buildings are usually blackened by black smoke; even if a new house is completed, it is usually necessary to set up a fire-fighting pool indoors, and use incompletely burned black charcoal to smoke on the house walls to allow people to live in.

\subsection{The Application and Connotation of Yellow in the Yi Architectural Decoration}

Among the main decorative colors of traditional Yi buildings, in addition to black, yellow is also their favorite decorative color. The facades of traditional Yi buildings are usually painted with yellow lacquer with patterns. In the tradition of the Yi people, yellow symbolizes harvest and beauty (Zeng Zhixiang, 2018) [5], and the natural primary colors of the motherland and the earth. It is believed that the main symbol of yellow is the color of "land", and it also symbolizes kindness and deep ethnic friendship, and symbolizes the noble character as precious as gold. The matrilineal traditional culture of the Yi nationality originated from the Yellow River because the motherland gave birth to a great nation and mankind in this land of the Yellow River, so that the Yi nationality's beautiful life can be preserved and continued for a long time. In addition, it is also a symbol of the maturity of corn, barley and other grains, representing a good harvest, abundance, and joy.

\subsection{The Application and Connotation of Red in Yi Architectural Decoration}

Among the traditional architectural decoration colors of the Yi nationality, red is also widely used. The reverence and worship of the sun and fire by the Yi people is the reason why red is widely used in the decoration of Yi buildings. The Yi 
people regard red as the color of life. Red symbolizes auspiciousness, joy, enthusiasm, and contains the strong cultural feelings of the Chinese nation. It is clearly recorded in the ancient Yi nationality's famous heroic epics "Lotto", "Chamu", "The Origin of All Things" and the ancient Yi nationality torch festival folklore. The Yi people have learned to use the sun and fire to replace natural lighting, heating and processing. Food has greatly improved the viability and living standards of the Yi people. The sun and fire occupy a special place in their lives, symbolizing the source of life, and becoming the foundation of all things in the world. Naturally, they gradually become the main belief objects for worship and sacrifices of the Yi people. Torch Festival is a traditional festival of the Yi people around June 24 every year. On this day, the masses of the villages in the Yi district reunited with their families to have a sumptuous family reunion dinner, slaughtered pigs and sheep, sacrificed to the god of fire, and prayed for the safety of the whole family, the prosperity of the five crops and the prosperity of the six animals. The Yi people advocated fire before death, and cremation after death, which shows that the sun and natural fire occupy a particularly important position in their body and mind. At the same time, red is widely regarded by the Yi people as a brave and passionate national spirit.

\section{The Use of Pattern Decoration in Yi Architecture and Its Symbolic Significance}

\subsection{The Application and Meaning of Plant Decoration Patterns in Yi Architecture}

Yi artisans apply this totem worship to various details or decorations of modern Yi buildings. The patterns or totems on these building components often appear directly in the form of various paintings and sculptures on some of the overall or detailed building components of the Yi buildings, becoming the most prominent "symbols" in architecture that embody ethnic characteristics. At present, the most common decorative patterns of plant and flower totems in the decoration of traditional building components of the Yi nationality. The main types of decorative patterns include golden silk bamboo pattern, soma flower, gourd pattern and long curl clover pattern, peony pattern, pomegranate pattern, lotus pattern, hibiscus pattern, and lotus pattern. In general, it can be said that the pattern of the $\mathrm{Yi}$ is a natural pattern shape directly formed by extracting a part of the flowering plant with the most characteristics of its natural physiological morphology, and all the patterns of a natural flowering plant can have multiple pattern combinations. The patterns of most plants and flowers basically reflect the early agriculture and production conditions in the geographic area. The doors and windows of the Yi people usually have plant patterns, carved with plum blossoms, gourds, corn, etc, which collectively express the spirit of nature and primitive worship in the hearts of local people. The embossed patterns of doors and windows in the traditional houses of the Yi nationality are mostly continuous circular or diamond-shaped geometric shapes. Different shapes of 
windows greatly enrich and activate the structure and appearance of the building. The relief patterns of doors and windows are mainly concentrated on the slab walls, columns and main columns of the house. Plant doors and windows are mainly decorated with sorghum, bamboo and wheat ears. Guozhuang stone carved patterns of grain and vegetable plants such as wheat and sorghum are full of life style.

\subsection{The Application and Meaning of Animal Decorative Patterns in Yi Architecture}

Animal patterns: Hunting is the most basic way of survival and activity for ancient humans. Humans obtained food through this hunting method, and at the same time greatly deepened their belief in certain animals and totem worship. The ancestors of the Yi not only used these animal patterns as architectural decorations, but also used them as the main objects of traditional totem worship. They were applied to various important parts of the architectural decoration of the $\mathrm{Yi}$, conveying the good wishes of the ancestors of the Yi nationality to be protected by their ancestors. In the traditional architectural decoration of the Yi, the patterns are mainly three common characteristic and representative animals: sheep, tigers and cattle. In the past, there was such a saying among the Yi people. Since ancient times, the traditional food culture of mankind has been able to survive, and have children to reproduce and raise offspring by sucking the milk of the cow king. In the past, most Yi people would offer ox horns in the halls of their homes. This is the main manifestation of the ancestors of the Yi people's spirit of admiring cattle. They hope that the horns can drive away evil spirits and avoid disasters and protect safety. Secondly, cattle is the most important agricultural and production material of the $\mathrm{Yi}$, and the main source and composition of the economic wealth of the Yi family. In order to drive away ghosts and evil spirits, the Yi people usually hang sheep horns, ox horns, canine teeth, or collar bones under pigs on the doors of houses.

\subsection{The Application and Meaning of Decorative Patterns of Natural Scenery in Yi Architecture}

Decorative patterns of natural scenery: Mainly manifested as waves and swirls of natural landscapes, which are related to the flow speed of natural world landscapes. The landscape pattern of the natural world evolves from the flow of natural landscapes, and there are some stars, moon, sun, and solar halo patterns, these patterns are closely related to the Yi people's astronomical astrology research in this period. These natural landscapes and scenery patterns of the Yi people generally correspond to or combine with some animal images such as cockscombs, and are mostly used for painting or direct carving on the eave pillars of some traditional Yi arctecture. The upper eaves are often painted or carved with natural landscape and scenery patterns such as the sun, moon, and stars. The two sides of the eaves are lined with door frames, and circular or 


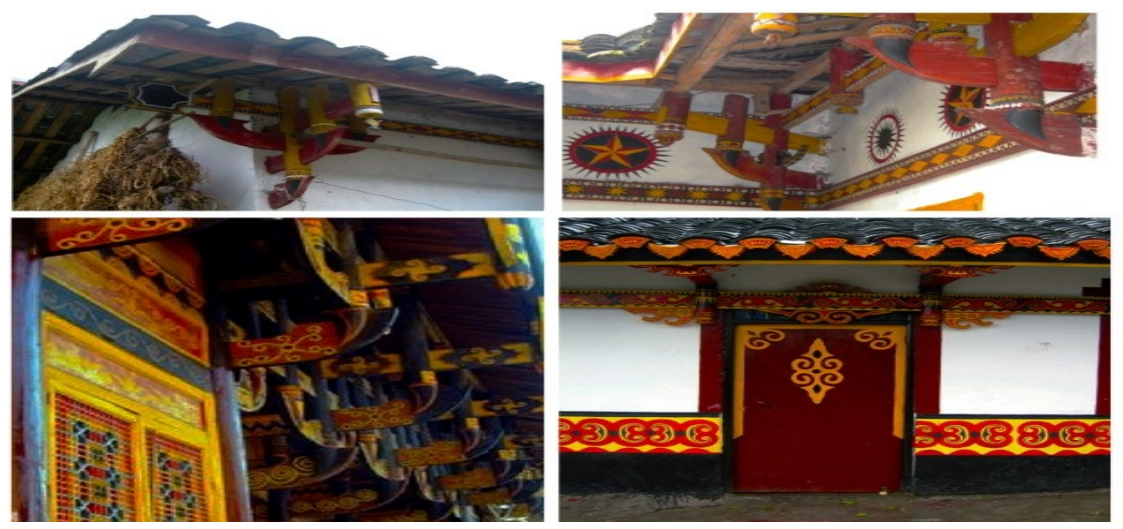

Figure 2. The patterns of plants, flowers, animals and natural landscapes in the detailed totem decoration of Yi (photo source: Internet).

diamond patterns are painted or carved. Some wealthy families and large families in the Yi village often show the Mid-Autumn Festival every year. On the gates of the traditional houses of the Yi people, painted some wild animal patterns carved with the moon and the sun, reflecting people's love and spiritual worship for the natural sun, moon, stars, landscape, and fully demonstrates the Yi people's commitment to protecting nature in the new era. Love and spiritual awe. Figure 2 shows the patterns of plants, flowers, animals and natural landscapes in the detailed totem decoration of Yi.

\section{Conclusion}

Among the various traditional architectural elements in the same historical region and cultural environment, architectural decoration is widely regarded as the "label" that can best reflect and fully reflect the characteristics of ethnic minority architectural culture. The decorative colors and decorative elements of traditional Yi buildings mainly reflect the traditional religious beliefs and folk culture of the local Yi people, and are an intuitive reflection and expression of the aesthetic concepts, status and identity of the local residents' traditional culture. The detailed decoration of traditional Yi buildings mainly includes the combination and application of the three architectural colors of red, yellow and black, as well as the color decoration of architectural totems and detailed architectural patterns. Totems and detailed patterns mainly include plant patterns, animal patterns, and natural scenery patterns. The architectural decoration of the $\mathrm{Yi}$ is unique and artistic, understanding its symbolic significance and applying it in the actual construction and design process can not only inherit the ancient architectural culture and civilization of the Yi, but also improve the national characteristics and artistic aesthetics.

\section{Conflicts of Interest}

The author declares no conflicts of interest regarding the publication of this paper. 


\section{References}

[1] Wen, Q. (2015) Research on Traditional Settlements and Architecture of Yi People in Southwestern China. Chongqing University, Chongqing.

[2] Fan, M. and Cheng, B. (2008) The Characteristics of Liangshan Yi Folk House Decoration Art and Its Philosophy. Sichuan Architecture, 1, 32-33+36.

[3] Song, L.F. (2006) An Analysis of the Symbol System of Liangshan Yi Nationality's Decorative Art. Southwest Jiaotong University, Chengdu.

[4] Chen, X.Q. and Tang, L.Y. (2019) A Probe into the Architectural Forms and Decorative Art of Liangshan Yi People's Traditional Houses. Design, 32, 158-160.

[5] Zeng, Z.X. (2018) Research on the Regional Expression of Landscape Architecture in Liangshan Prefecture Tourist Attractions. Southwest Jiaotong University, Chengdu. 